\title{
Interpretation of as-placed cemented paste backfill properties from three mines
}

\author{
MW Grabinsky University of Toronto, Canada \\ D Simon University of Toronto, Canada \\ BD Thompson Mine Design Engineering, Canada \\ WF Bawden Mine Design Engineering, Canada \\ RL Veenstra AMC Consultants Pty Ltd, Australia
}

\begin{abstract}
Over the last few years considerable attention has been paid to predicting the as-placed properties of cemented paste backfill (CPB) using laboratory techniques that load the sample in ways that are thought to reasonably simulate the effective stress paths experienced by the CPB during initial placement and subsequent curing while backfilling is ongoing. Most of these studies suggest that consolidation mechanisms prior to significant hydration-induced stiffness increases are responsible for denser CPB and correspondingly higher strengths. The field evidence for significant density increases during placement, however, is mixed with some studies indirectly suggesting increased density may occur and some studies with direct field measurements showing no significant density increases.

This paper presents three case studies in which very careful and detailed field measurements were taken during backfilling, and for which considerable success was achieved in subsequent field sampling to directly measure densities of as-placed CPB. The three mines cover a range of mining conditions with some narrow Alimak stopes, some large and some small stopes, at three different mining operations in two countries (two operations in good quality Canadian Shield host rock, and one in relatively poor host rock conditions in Turkey). Even for this seemingly wide range of mining conditions, the field results were similar and compelling; very little water was lost between transported and cured samples, and therefore the density increased only very marginally. For all three mines the field measurements collected during filling suggests that effective stresses remain essentially zero for a prolonged period (many hours) during filling. Evidence for hydration during this zero effective stress stage includes changes in temperature and electrical conductivity, which can be correlated to laboratory measurements on similar samples. Therefore, the material essentially hydrates under a zero effective stress condition and gains sufficient stiffness to withstand subsequent loading under non-zero effective stresses with very little change in density.
\end{abstract}

The question then to be asked is 'why' does this prolonged period of zero effective stress exist? Some insight can be gained from modified Gibson analytic solutions but the most compelling explanation is derived from numerical modelling based on a Gibson approach for fully coupled stress-deformation-fluid transport analysis. The boundary conditions for such modelling are non-trivial and are considered in detail in a companion paper by Veenstra et al. (2013), but the consistency of the numerical solutions with the extensive field data collected suggests that the modelling approach has merit.

Finally, for mines where such conditions exist, it appears that very little can be done through altering the deposition technique in order to affect the consolidation processes to increase density. In such cases, the only solution may be to use water reducing admixtures and such an approach is briefly addressed.

\section{$1 \quad$ Introduction}

Rapid backfilling techniques are a critical component of modern mining methods, especially in high stress environments where ground cannot remain unsupported for long without accumulating risks of ground 
falls and rockbursts. CPB is now a popular backfilling method, especially for operations where ore is crushed finely to liberate small concentrations of valuable elements. Some key aspects of CPB made from fine tailings are its high solids concentration (as compared to hydraulic fills) and high water retention characteristics resulting from capillary action in the fine pore spaces. This results in very little water lost from the fill during deposition, and so water management during filling is virtually eliminated as compared to hydraulic backfill methods.

Although CPB's solids concentration appears to be high as compared to hydraulic fills, the relatively uniform grain size distribution typically results in void ratios around 1.0 (porosity around 0.5 ) which is actually very high compared to typical concrete mix design. As a result, CPB's strength as commonly characterised by its unconfined compressive strength (UCS) is very low as compared to a concrete mix design at the same binder content. This can be addressed somewhat by blending the paste with fairly broadly graded sand, such as esker sand as is used by Xstrata Copper Canada's Kidd Mine in Timmins, Ontario, Canada. When this is done, however, the sand reduces the total amount of tailings that can be returned underground, and therefore increases the volume of tailings to be managed usually through surface deposition.

The relatively low CPB strengths for amount of binder used is a significant cost consideration at many operations. The potential influence of self-weight consolidation during deposition and the resulting decrease in void ratio on strength has been demonstrated by Fahey et al. $(2010,2011)$ and Yilmaz et al. $(2009,2010,2011)$. However, whether or not self-weight consolidation is an important mechanism at most mining operations is not clear. Aref (1988) and Been et al. (2002) used cone penetration test (CPT) data to infer that self-weight consolidation had taken place, however, interpreting density from CPT measurements requires one to make an assumption regarding the effective vertical stress, and while this is a straightforward proposition for many geotechnical projects it is far from certain within a backfilled stope. Cayouette (2003) observed significant self-weight consolidation during backfilling but this was for an amended fill that used rheology modifiers. Reports of backfills where drilling and sampling were used are relatively rare. le Roux et al. (2005) carried out such a study at Golden Giant Mine in Marathon, Ontario, Canada and found no discernable trend with depth of fill for any of the bulk properties (void ratio, water content, or degree of saturation). Grabinsky et al. (2013) report similar findings for sampling carried out at Inmet's Cayeli Mine in Turkey, Barrick's Williams Mine in Marathon and Xstrata's Kidd Mine in Timmins.

The objective of this paper is to follow up on the field properties reported by Grabinsky et al. (2013) and to provide additional information in aid of interpreting the underlying causes for the observed in situ properties. But first the results from a limited laboratory study will be given to demonstrate the important effect density has on strength for backfill materials from two of the mines.

\section{Effect of void ratio on CPB strength}

The study described by Fahey et al. (2011) involved preparation of CPB poured into cylinders for subsequent UCS testing, and applying a surcharge to some of them at different times. When the surcharge was applied immediately the CPB underwent consolidation quickly (as compared to the hydration rate) and so became denser and gained strength. If the surcharge was placed after hydration was well underway, then the increased sample stiffness arising from hydration resisted the volume change and so the sample became neither as dense nor as strong as in the first instance. Samples that had no surcharge applied were the least dense and the weakest. The difference in strength for a $100 \mathrm{kPa}$ surcharge applied immediately, as compared to a sample where the surcharge was applied at 72 hours was a UCS $1.3 \mathrm{MPa}$ compared to $\sim 480 \mathrm{kPa}$, and corresponding dry densities $\sim 1.77 \mathrm{t} / \mathrm{m}^{3}$ compared to $\sim 1.62 \mathrm{t} / \mathrm{m}^{3}$. This result clearly demonstrates the desirable effect of increasing the density so as to enhance the effectiveness of the binder, a phenomenon that is well documented for concrete mix designs (Neville 1995).

To investigate this effect on the backfill for the mines considered here, Fahey et al.'s experimental approach was repeated for Williams and Kidd backfill materials. Unfortunately, all of the Cayeli Mine backfill materials had been consumed in other tests by the time this experiment was undertaken. 
The mines' backfill materials were prepared according to the mix designs used by the mines. The tailings are non-plastic silt-sized materials with plasticity index less than $\sim 5$ so that it only takes a few percent reduction in water content to go from a pumpable consistency to a semi-solid consistency. As such, it was found that when the samples were poured into the cylinder moulds there would be some self-weight consolidation that was essentially complete in less than one hour, well before hydration would be expected to start. For Williams Mine materials this amounted to a void ratio reduction from 1.06 to 0.98 , and a corresponding water content reduction from 39 to 36\%. For the Kidd Mine materials the void ratio reduction was from 0.67 to 0.60 and the water content reduction was from 25 to $22 \%$. (The conventional geotechnical engineering definition of water content is used here, that is mass of water divided by mass of solids.) These changes in water content are important for later comparison with results from field investigations.

Samples were either left unloaded or else loaded with a $100 \mathrm{kPa}$ equivalent surcharge within two hours, well before hydration would be expected to begin. For Williams materials this resulted in a further reduction in void ratio from 0.98 to 0.93 , and reduction in water content from 36 to $34 \%$; and for Kidd materials the reduction in void ratio was from 0.60 to 0.50 , and reduction in water content was from $22 \%$ to $19 \%$. The results shown in Figure 1 are for Williams backfill prepared at 3\% binder content (50:50 normal Portland cement:type C fly ash) and Kidd Creek backfill prepared at 2.2\% binder content (10:90 normal Portland cement:ground blast furnace slag). The testing was carried out at seven days, and it can be seen that both the Williams and Kidd materials about double in strength (from 150 to $300 \mathrm{kPa}$ ) with the early application of the $100 \mathrm{kPa}$ surcharge. It is therefore concluded that the potential strength gain arising from reduction in void ratio at the earliest stage possible would generally be desirable in backfilling operations.

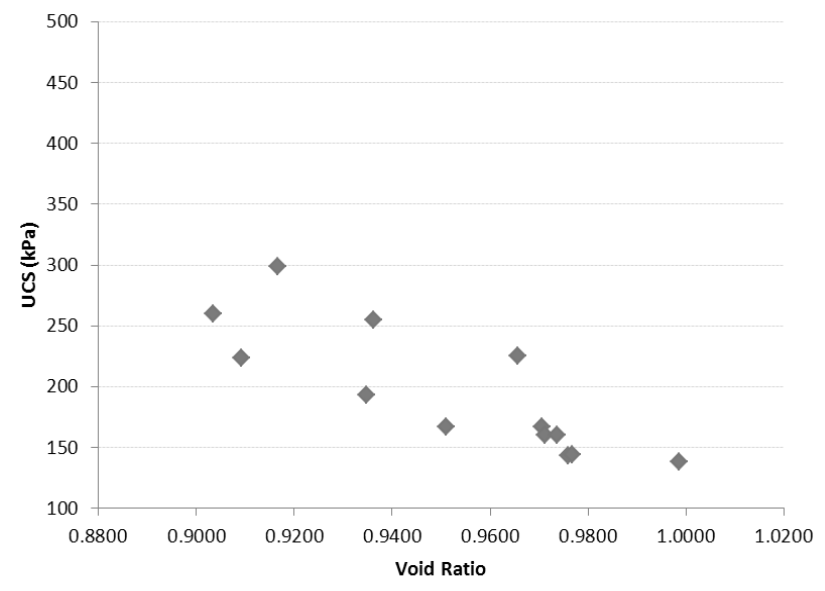

(a)

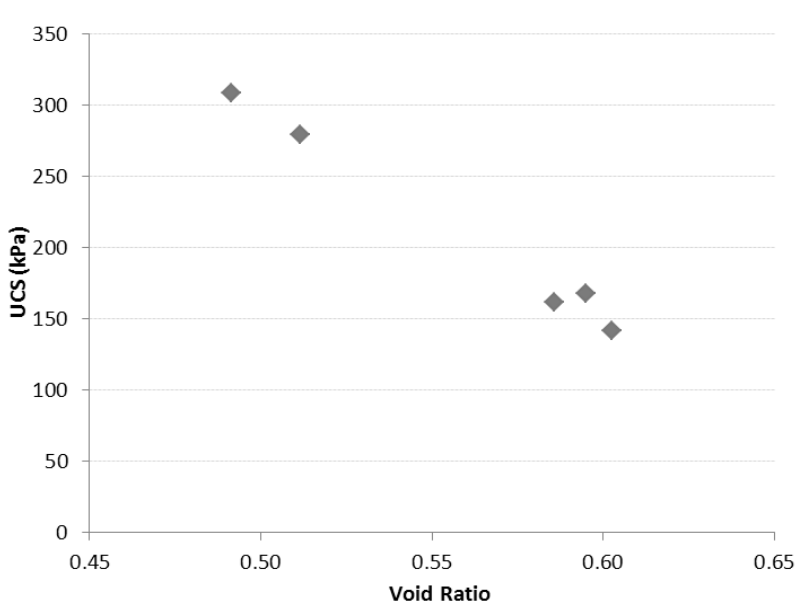

(b)

Figure 1 Seven day UCS of Williams (a); and Kidd (b) backfill materials as a function of sample void ratio

To better understand how quickly these changes in void ratio (or water content, assuming the backfill remains saturated) would have to occur relative to key stages of hydration, samples were also tested in the laboratory using the Vicat penetration test (ASTM C191), whereby a weighted steel needle is dropped onto the surface of a $40 \mathrm{~mm}$ deep sample, initially penetrating to the full depth; the initial set is defined when the needle only penetrates $25 \mathrm{~mm}$, which correlates to the condition of limited 'workablility' in concrete materials. Changes in Vicat needle penetration are correlated with electrical conductivity (EC), as it has been shown that EC changes with the different stages of hydration (Simon \& Grabinsky 2012). Upon first mixing, i.e. 'time zero' with respect to the hydration process, the binder reacts with the water and the Portland cement particles begin to dissolve, thereby increasing the ion content of the water and hence increasing the bulk EC. The EC then decreases as these ions are pulled out of solution to form the physical hydration products which increase the material's strength and stiffness (normally at around four hours for Portland cement pastes). This is shown in Figure 2 for the Cayeli backfill materials. For Cayeli, the binder 
used is from a plant located in Turkey (CEM II / A $42.5 \mathrm{R}$ manufactured by Unye Cement) and although it is generically described as a normal Portland cement, it actually contains larger amounts of pozzolans than would be the case for a Canadian Type 10 cement. Its hydration exhibits two peaks, and the second of these roughly correlates with the initial set as defined through the use of the Vicat penetration test.

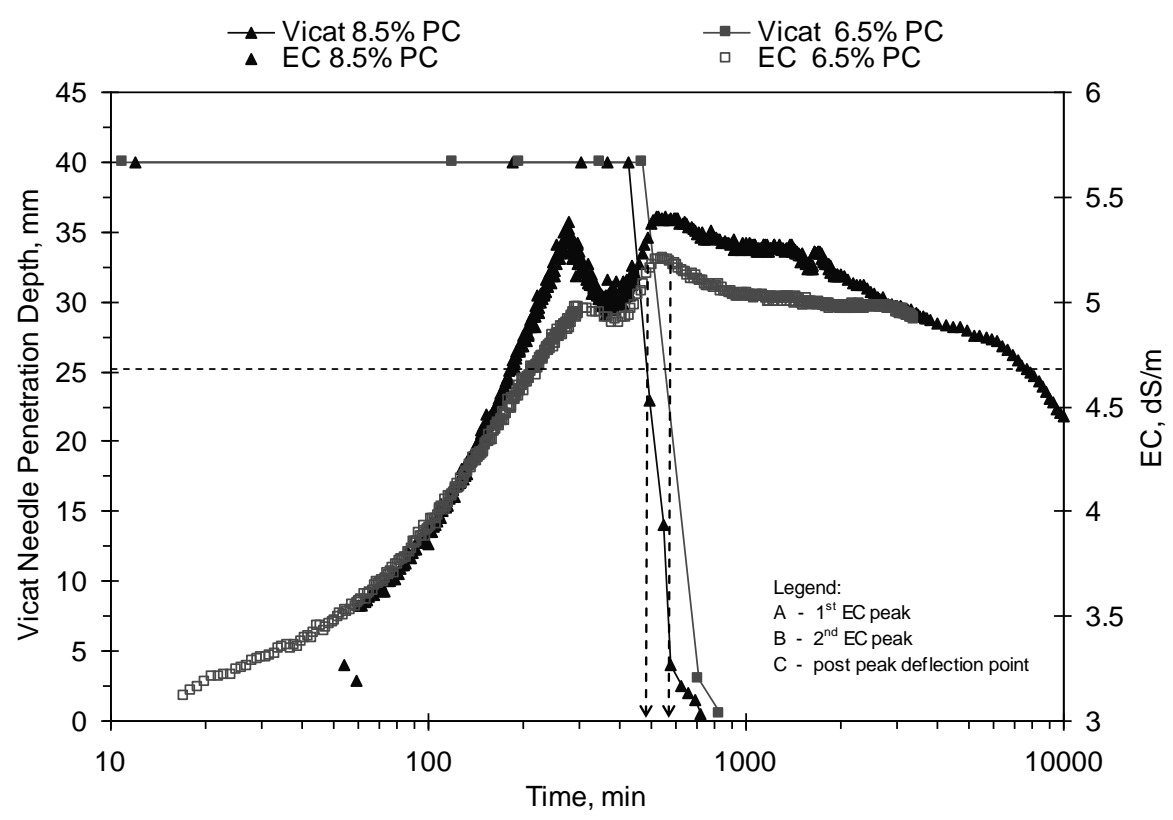

Figure 2 Vicat needle and EC laboratory test results on Cayeli Mine backfill materials

Results similar to Figure 2 were also obtained for Williams CPB. The Vicat penetration test can be used on the tailings paste portion of Kidd Mine's CPB, but it cannot be applied to the CPB when it contains the esker sand because the larger sand particles would bias the test result. However, Galaa et al. (2012) have shown that small strain triaxial cyclic loading can be used to determine the evolution of elastic parameters with time (Figure 3). The development of early stiffness at about six hours for the $4.5 \%$ binder content is consistent with the drop in EC measured in control samples, again suggesting that EC peaking/dropping is associated with the development of hydration products that strengthen and stiffen the material.
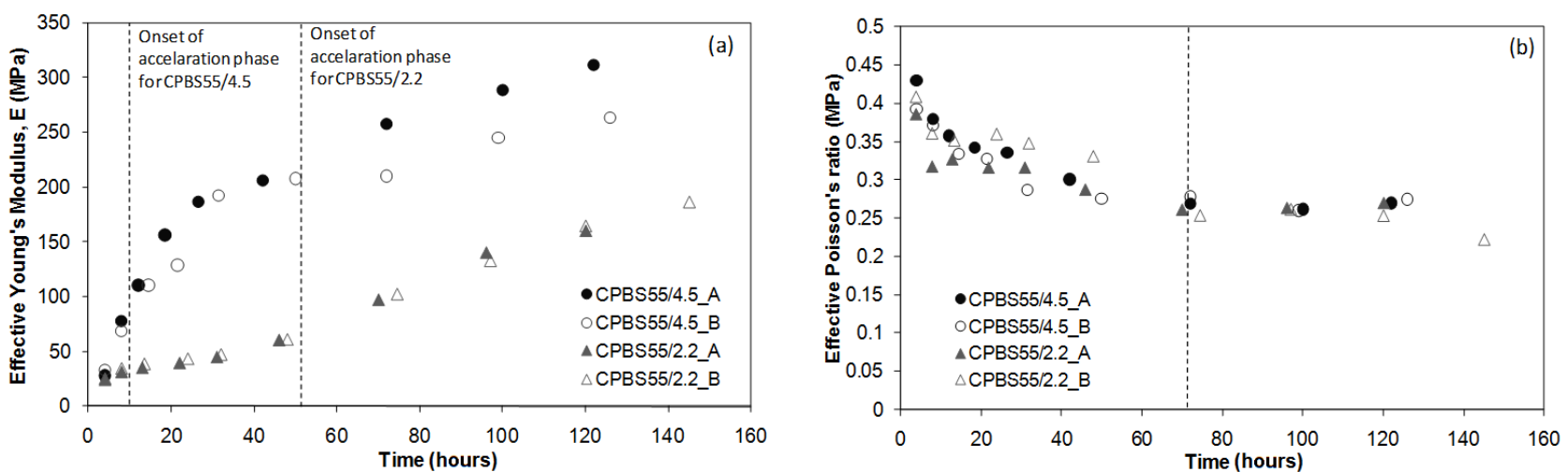

Figure 3 Development of $E$ and $v$ in Kidd backfill between four and 140 hours

The next section presents the background to the three case studies and considers the mechanisms that may have led to the observed changes in bulk properties from the as-prepared to the as-sampled backfill.

\section{Description of the case studies}

The field studies were carried out at Williams Mine, Kidd Mine, and Cayeli Mine. These three locations will be referred to as $\mathrm{W}, \mathrm{K}$ and $\mathrm{C}$, respectively. The mines' materials, stope geometry, mix designs and filling 
strategies are considered in this section. Williams and Cayeli mines have backfill plants that use tailings from their own milling operations. Kidd Mine ships its ore to a comparatively distant metallurgical plant and thus economic paste production was realised by dredging old gold tailings from a nearby closed tailings pond to produce the paste, which is then blended with alluvial sand to fine gravel from a nearby esker, in the ratio of $45 \%$ tailings to $55 \%$ sand (Figure 4 ).

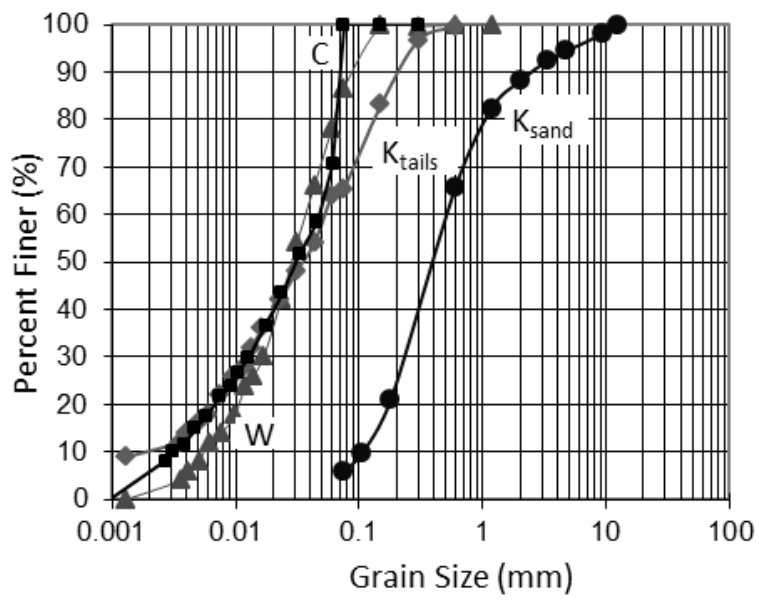

Figure 4 Grain size distributions for backfill solids

The tailings mineralogy of Kidd and Williams mines were predominantly non-clay minerals; only Cayeli had some clay mineralogy (kaolinite, dickite, and chlorite totalling $7.8 \%$ by mass). The specific gravity, Gs of Williams and Kidd mines' materials were around 2.75 while Cayeli's was higher ( 3.7 when combined with the binder). The typical CPB mix designs, given in Table 1, result in a slump in the range $15-20 \mathrm{~cm}\left(6-8^{\prime \prime}\right)$, with the upper range being more common for ease of pipeline transport.

Table 1 Typical backfill mix designs and bulk properties

\begin{tabular}{cccccc}
\hline Mine & $\begin{array}{c}\text { Fill } \\
\text { area }\end{array}$ & $\begin{array}{c}\text { Binder } \\
\text { (\%) }\end{array}$ & $\begin{array}{c}\text { Water } \\
\text { content }\end{array}$ & $\begin{array}{c}\text { Void } \\
\text { ratio }\end{array}$ & $\begin{array}{c}\text { Relative } \\
\text { density }\end{array}$ \\
\hline W & Plug pour & 3.0 & 0.38 & 1.06 & 1.87 \\
& Main pour & 3.0 & 0.38 & 1.06 & 1.87 \\
K & Plug pour & 4.5 & 0.25 & 0.68 & 2.01 \\
& Main pour & 2.4 & 0.26 & 0.70 & 2.00 \\
C & Plug pour & 8.5 & 0.33 & 1.22 & 2.22 \\
& Main pour & 6.5 & 0.33 & 1.22 & 2.22 \\
\hline
\end{tabular}

The Williams Alimak test stope was approximately 5 by $30 \mathrm{~m}$ in plan dimensions and $149 \mathrm{~m}$ high at an inclination of $69^{\circ}$ to the horizontal (Figure 5). Backfilling took place in several stages, as indicated in Figure 5. A 46 hour cure period followed completion of the $8 \mathrm{~m}$ high plug pour. The main pour was interrupted twice due to operational issues. Constant binder content at $3 \%$ was used throughout. The travel time in the pipe from paste plant to stope was about 30 minutes. In the plug the average fill rise rate was $0.36 \mathrm{~m} / \mathrm{h}$ and in the main pour the average fill rise rate was usually around $1.33 \mathrm{~m} / \mathrm{h}$.

The Kidd longhole stope was approximately 15 by $30 \mathrm{~m}$ in plan dimension with a $32 \mathrm{~m}$ fill height (Figure 5). The filling history is shown in Figure 5. A $6 \mathrm{~m}$ high, 4.5\% binder content CPB plug was poured and then the CPB was immediately switched to a $2.2 \%$ binder CPB for the remainder of the pour. Although a continuous pour was planned, operational problems resulted in a staged pouring. It should be noted that rise rate was generally uniform at about $0.25 \mathrm{~m} / \mathrm{h}$ and this is significantly less as compared to the narrow Williams Alimak upper stope. The travel time in the pipe from paste plant to stope was about one hour. 
The Cayeli longhole stope was approximately 10 by $25 \mathrm{~m}$ in plan dimension with a $16 \mathrm{~m}$ fill height (Figure 5). An $8 \mathrm{~m}$ high plug with $8.5 \%$ binder CPB was poured immediately followed by the remainder of the fill at $6.5 \%$ binder CPB. The pour was continuous and the average rise rate was $0.23 \mathrm{~m} / \mathrm{h}$ (virtually the same as for the Kidd test stope). The travel time in the pipe from paste plant to stope was about 15 minutes.

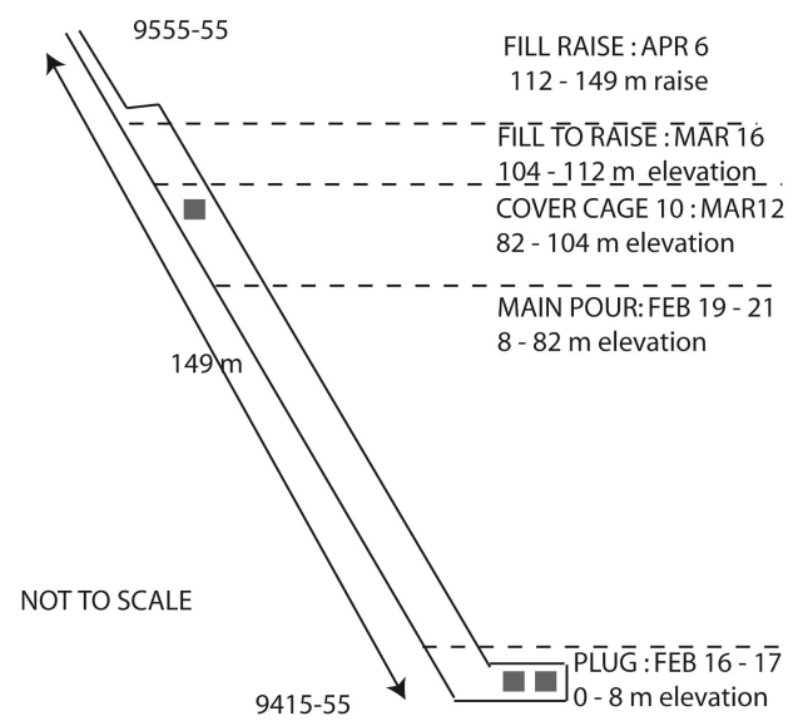

(a)

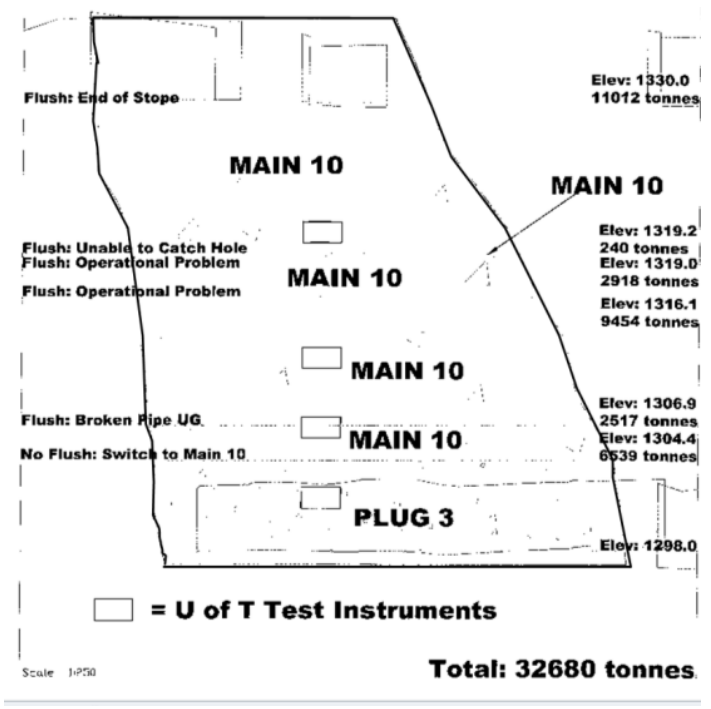

(b)

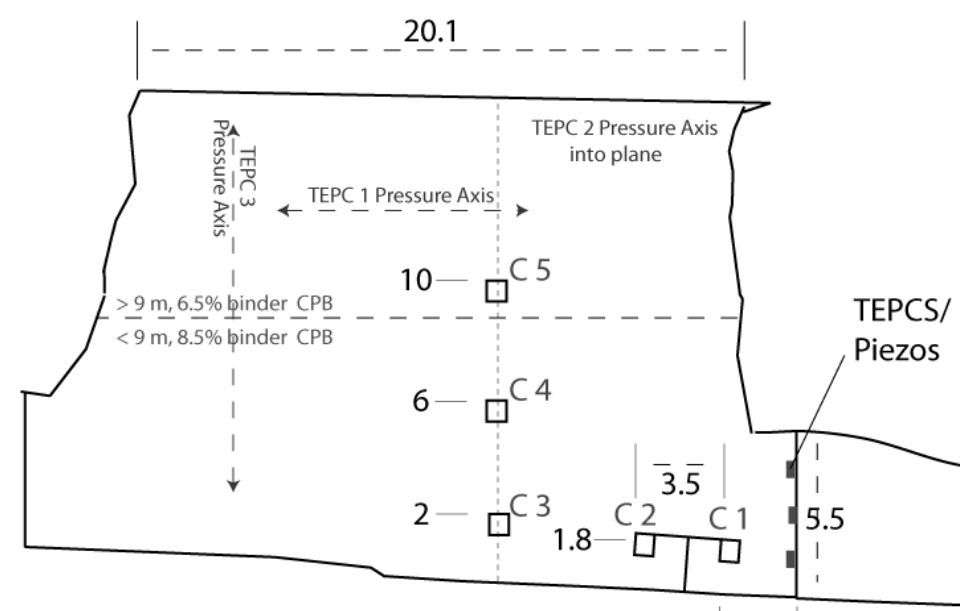

(c)

Figure 5 Stope geometries and filling strategies; (a) Williams; (b) Kidd; and (c) Cayeli

\section{$4 \quad$ Field sampling results}

For each mine the barricade was eventually removed to facilitate mining of adjacent stopes, thereby enabling block sampling of the cured paste from the backfilled undercut region.

Coring was also attempted. Kidd Mine's backfill is the strongest and samples were successfully taken throughout the height of the Kidd stope. Williams Mine's backfill was the weakest and coring was conducted with some difficulty, although sampling in multiple undercut locations and along most of the backfill height was eventually successful. Cayeli Mine had no experience coring their backfill and the equipment available at the time of testing was not well suited to obtaining undisturbed specimens, so unfortunately only the block sampling data in proximity to the barricade was available. 
At Williams Mine sampling was conducted in the paste plant to determine as-prepared water contents ranging from $0.36-0.42$ with an average 0.385 , corresponding to a saturated void ratio of 1.04 . Virtually the same water contents were determined from samples near the barricade and throughout the height of the stope, as shown in Figure 6 . Note that the samples are virtually saturated so presenting results in terms of void ratio or water content will lead to the same observation that the bulk properties are essentially uniform with location, suggesting that no significant form of self-weight consolidation, or any other densification process is acting during the deposition of this material.

void ratio

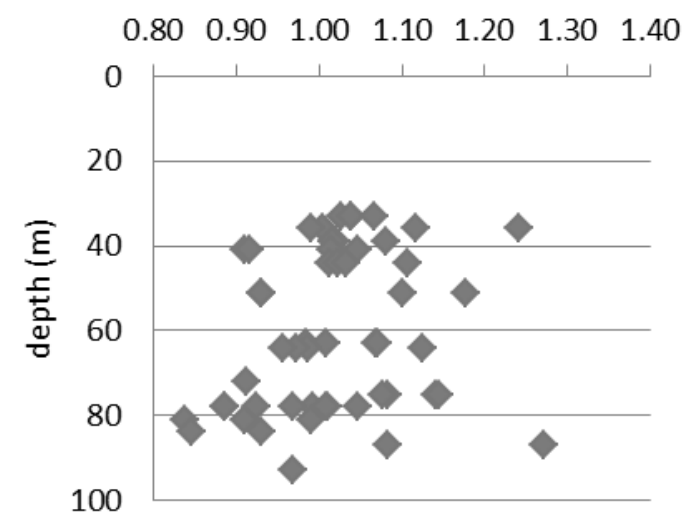

Figure 6 Field void ratios for Williams backfill, plotted with depth of backfill

Sampling at Kidd's paste plant determined the process variations in water content to be between 0.235 and 0.28 with an average 0.25 . The as-prepared water was largely retained in the fill mass, but during placement air became entrained in the fill as evidenced by visible voids in the block sample. Steps were taken to ensure visible voids were not present in any of the samples used to determine bulk properties, however the voids plausibly exist at microscopic levels as well and therefore are reflected in the results shown in Figure 7, which is similar to the results presented by le Roux et al. (2005) for Golden Giant Mine.

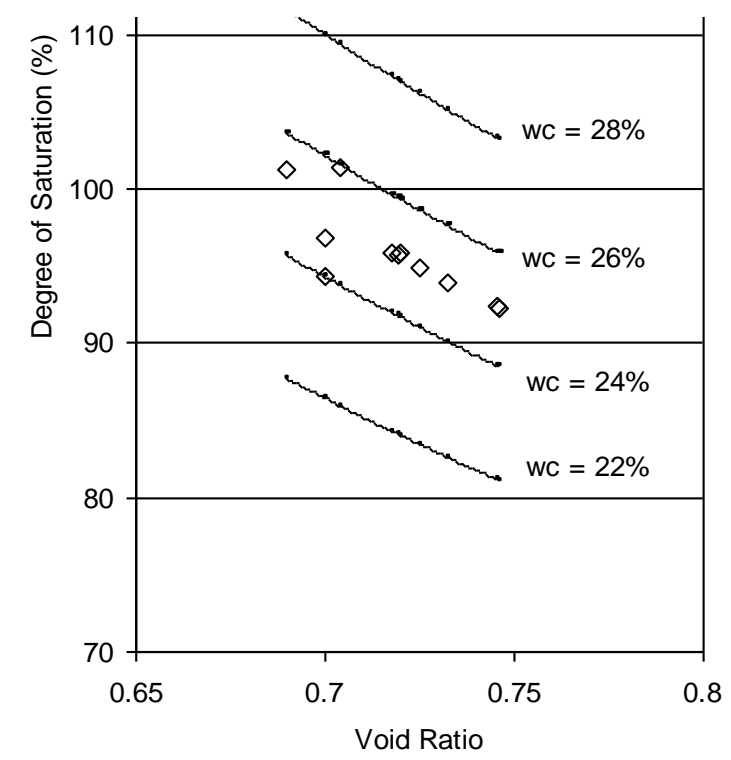

Figure 7 Bulk properties for field samples obtained from Kidd backfill

Air voids were also present in the Cayeli block samples, and bulk properties were only evaluated for samples that did not contain visible voids. The water contents determined from the paste plant showed a process variation ranging from 0.28 to 0.37 with an average 0.33 . The samples tested for bulk properties from the block sample had water contents between 0.30 and 0.34 with an average of 0.33 , again suggesting that virtually no water was lost during deposition. 
For all three of the case studies presented it appears that the rate of backfill stiffness and strength gain due to binder hydration is effectively preventing any self-weight consolidation effects from occurring. Further evidence in support of this explanation is given in the next section.

\section{$5 \quad$ Field monitoring results}

Grabinsky et al. (2013) presented field monitoring results for the three case studies, in terms of total and effective stresses and pore water pressures, and temperatures that develop during filling and subsequent curing. More detailed description and analysis can be found in Thompson et al. (2011), and in the free online Canadian Geotechnical Journal article by Thompson et al. (2012). An example of this is shown in Figure 8. When the backfill first reaches the instrumentation cluster (or 'cage'), the total stresses and pore water pressure rise uniformly as a function of the overburden slurry weight of the unhydrated fill. The ideal situation occurs when the pore water pressure begins to drop off and the total stresses diverge, indicating the onset of effective stress within the backfill. This onset of effective stress development is typically preceded by a rise in temperature associated with the exothermic binder hydration reactions. However, heat generation begins before the solidifying hydration products are actually formed, and continues to increase throughout the reaction process. In contrast, EC changes can be used to assess the onset of hydration indicated by increasing EC, followed by the development of the hydration products indicated by decreasing EC. Therefore only an integrated interpretation of both EC and temperature changes provides compelling evidence for when the hydration products actually form, and therefore when the backfill should be expected to be able to carry load.

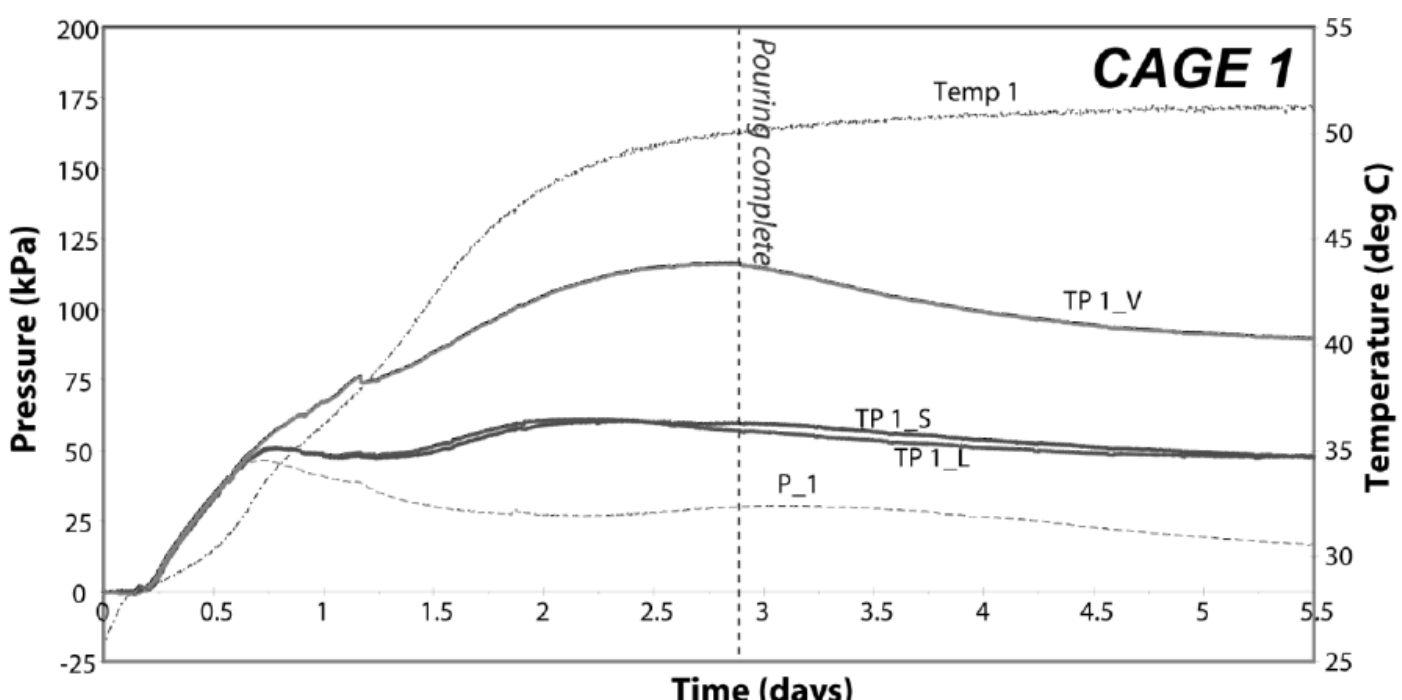

Figure 8 Example of total stress, pore water pressure, and temperature monitoring at Cayeli Mine (Temp is temperature; $P$ is porewater pressure; TP is total pressure with secondary identifier denoting vertical, and short and long horizontal axes)

Figure 9 shows results for one of the instrumentation clusters located near the barricade in a Kidd stope. At 21.3 hours from the start of the pour the backfill covers the instruments and registers a distinct rise in temperature, total stress and pore water pressure. The temperature continues to increase relatively slowly, from about $25-27.5^{\circ} \mathrm{C}$ over the shown monitoring period. The EC shows a distinct rise from $25-26$ hours, peaking at 26 hours and declining gradually thereafter. As mentioned previously, it takes about an hour for Kidd paste to travel from the plant to the stope, so the time from mixing to reaching peak EC is at least $1 \mathrm{~h}+(26-21.3) \mathrm{h}=5.7 \mathrm{~h}$, not accounting for time the paste may have spent flowing over the deposition surface to reach the instrumentation cluster. The approximate time of 6 hours corresponds well with the onset of stiffness observed in laboratory triaxial tests as previously shown in Section 2. Note also that it is in this 25-26 hour timeframe that effective stresses begin to develop, indicating that the material has formed load-bearing capacity. Also recall that the samples retrieved from the field showed remarkably little change 
in water content, therefore it seems unreasonable to assume that the observed effective stresses are a result of significant drainage through the fill mass. Possible mechanisms to explain changes in water content will be considered in the following section.

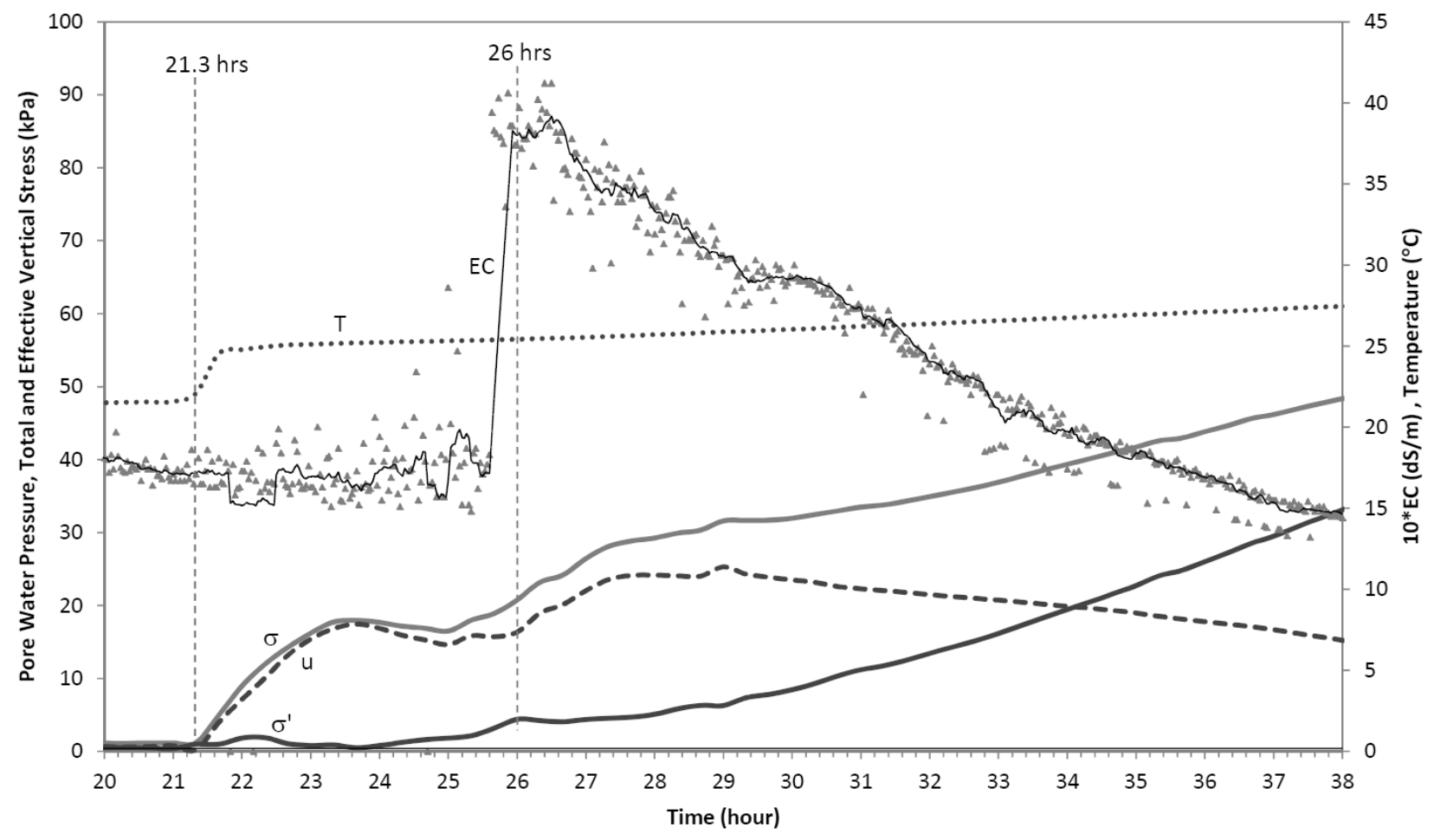

Figure 9 Electrical conductivity (EC), stress (total stress $\sigma$, porewater pressure $u$ and effective stress $\sigma^{\prime}=\sigma-U$ ) and temperature $(T)$ results for Kidd CPB

Figure 10 shows results for one of the instrumentation clusters located in the upper portion of the Williams Alimak stope (Cluster 10), and compares results to EC data determined on a laboratory sample. It can be seen that laboratory and field EC results have peaks at similar times (about 0.6-0.7 days, or around 15 hours). The temperature monotonically increases from about $17-20^{\circ} \mathrm{C}$ over the shown monitoring period. The pour covering this instrumentation cluster actually ends a few hours after covering the instruments, at which point the total vertical stress has peaked at about $60 \mathrm{kPa}$ and starts to decrease. Normally it would be expected to see pore water pressures identical with the total stress, but it is believed that the pore water pressure transducer was left in the open stope too long (over a month) and had started to desaturate, thereby under-reading the actual water pressure and making it slower to respond to changes in pressure. Regardless, it can be seen that just before the peak of the EC curve, as well as coincident with the EC peak there are slight changes in the response of both the total and water pressures, and by this point in time there is a significant difference between the two implying the development of effective stress, and therefore load-carrying capacity of the backfill. Recall from the previous section that samples subsequently taken from this area of the fill showed bulk properties that were virtually identical to the as-prepared backfill, and therefore, as was the case for the Kidd backfill, the observed development of effective stresses cannot reasonably be attributed to drainage mechanisms.

The final example comes from the Cayeli field study (Figure 11). Vicat and EC results were shown previously for Cayeli backfill materials in Section 2 and it would normally be expected that significant strength and stiffness gains would be achieved by about 10 hours. Figure 11 shows that the backfill covers the instrument cluster at about hour seven into the pour. There is a subsequent monotonic rise in both temperature and EC, but even by 13 hours later there is no indication from the EC that any significant hydration reaction has occurred, and by this point the safe barricade pressure rating had been reached and so the pour was stopped. At about 60 hours since the start of the first pour there was a significant rise in both EC and temperature and so the pour was resumed (with appropriate risk management strategies in 
place) and the remainder of the pour was successfully completed. However, the EC monitoring never recorded the characteristic 'twin peaks' observed in the laboratory study, suggesting that the process of hydration in the stope was different from that in the laboratory. Investigations are ongoing to determine why these hydration discrepancies between laboratory and field exist.
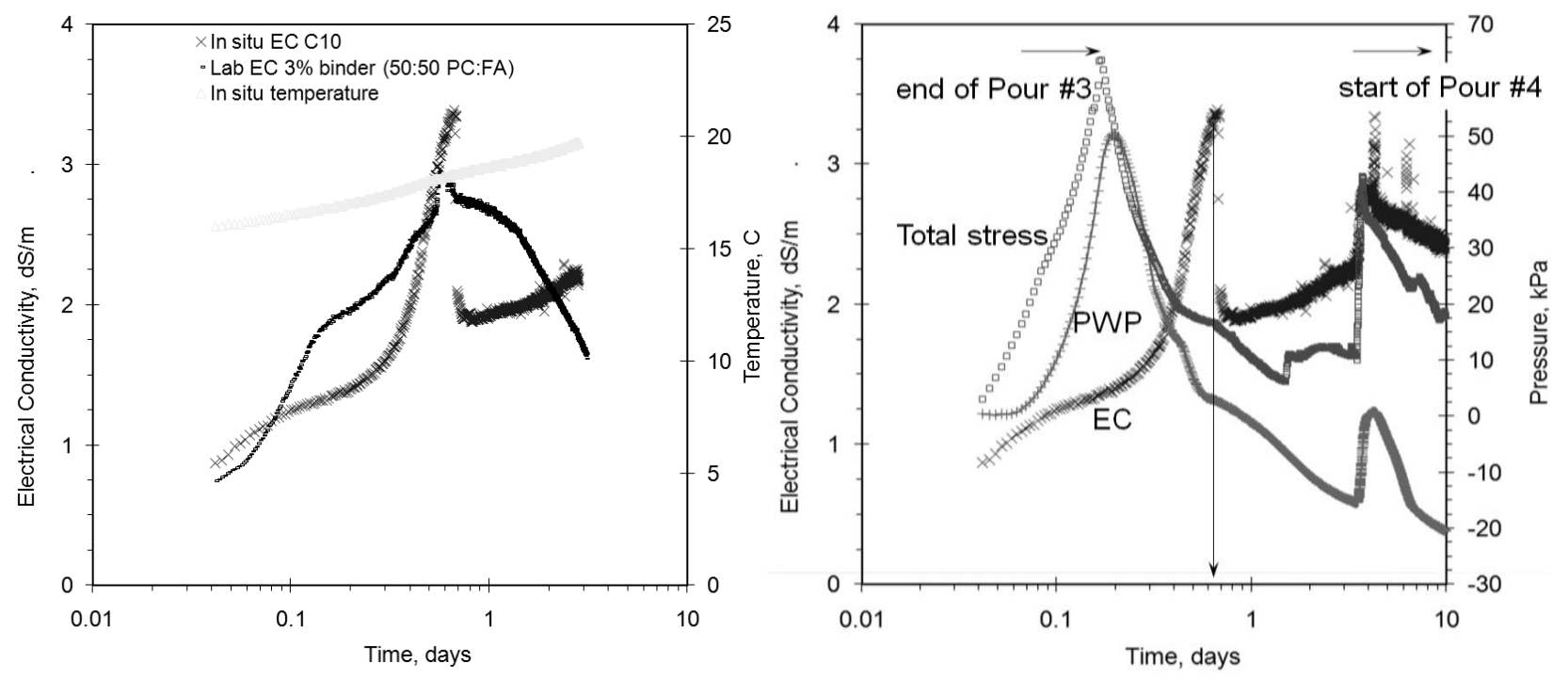

Figure 10 Electrical conductivity (EC), stress, porewater pressure (PWP) and temperature results for Williams CPB with 50:50 Portland cement (PC):fly ash (FA) binder

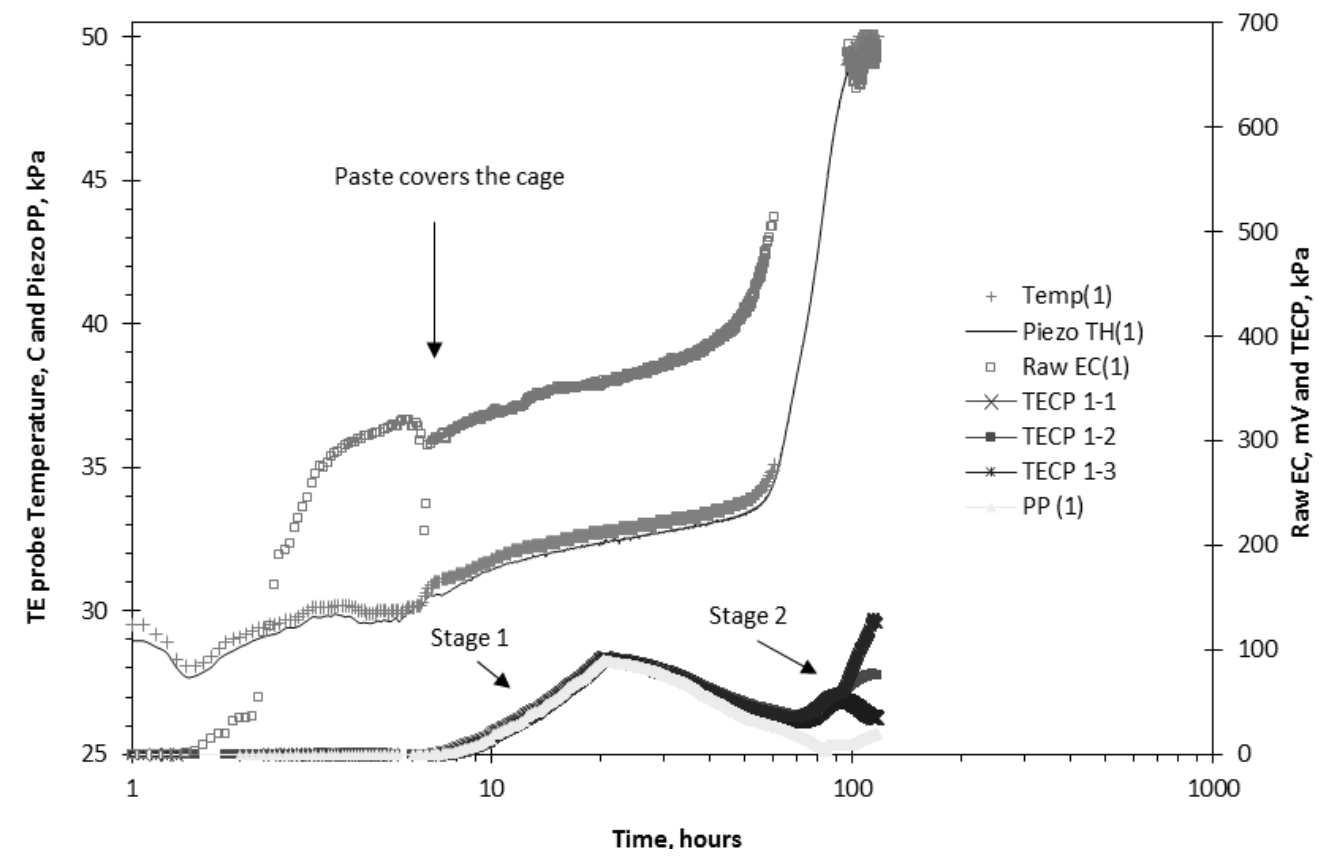

Figure 11 Electrical conductivity (EC), porewater pressure (PP), stress (TECP 1-1 vertical, and 1-2 and 1-3 horizontal) and temperature (Temp and Piezo TH) results for Cayeli CPB during filling stages 1 and 2

\section{Discussion}

In Section 2 it was noted that laboratory prepared samples exhibited virtually immediate self-weight consolidation when poured into cylinder moulds. The fact that all mines' sampled backfills had relatively high water contents suggests that the self-weight mechanism occurring in the laboratory cannot be occurring during field deposition. There are significant differences between these two 'deposition' techniques. Figure 12 shows a screen capture from a camera placed behind a barricade so as to image the 
deposition, and no clear fluid can be seen on the surface of this flow. Also in Figure 12 is a picture of paste-on-surface deposition from another mine with non-plastic silty tailings, and it can similarly be seen that as long as the paste keeps flowing the water remains effectively entrained in the pore space. The differences between traditional laboratory preparation techniques and actual field deposition processes can have important consequences: in particular, traditional laboratory preparation techniques will result in samples with lower void ratios than in the field, and will probably therefore over-predict the field strength.

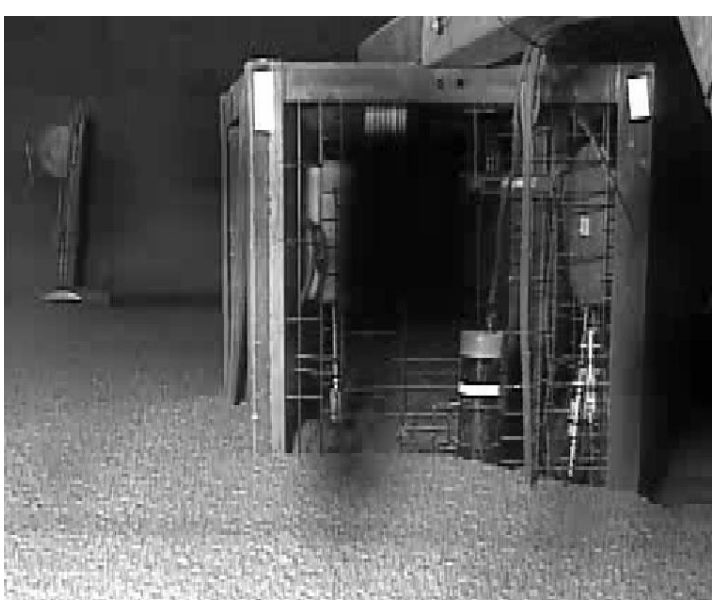

(a)

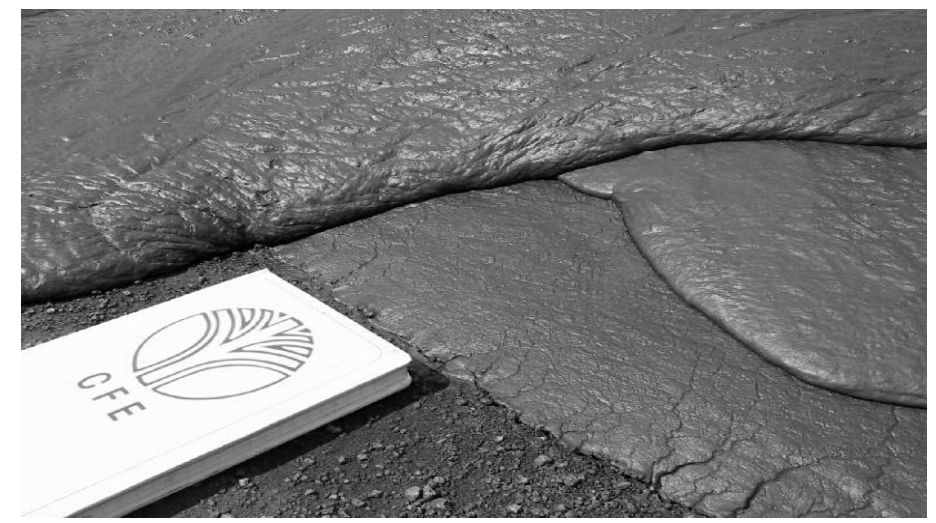

(b)

Figure 12 Image of lava-like flow of paste on the deposition surface and into an instrumentation cluster (a); and on surface (b)

Fahey et al. (2010) have also suggested using a modified form of Gibson's (1958) solution for determining pore pressures generated in accreting sediments. If early age consolidation coefficients are used for the pastes considered here, then the predicted normalised pore pressure distributions are as shown in Figure 13 when the end of the plug pours are reached. The instruments are typically located about mid-height in the plug and therefore the amount of pore pressure dissipation predicted by the Gibson solution is relatively small, even if the consolidation coefficient $c_{v}$ is considered constant. However, hydration affects both permeability and stiffness, and therefore also $c_{v}$; and so the actual analysis needs to be more sophisticated and requires numerical analysis, as has been demonstrated by Veenstra (2013).

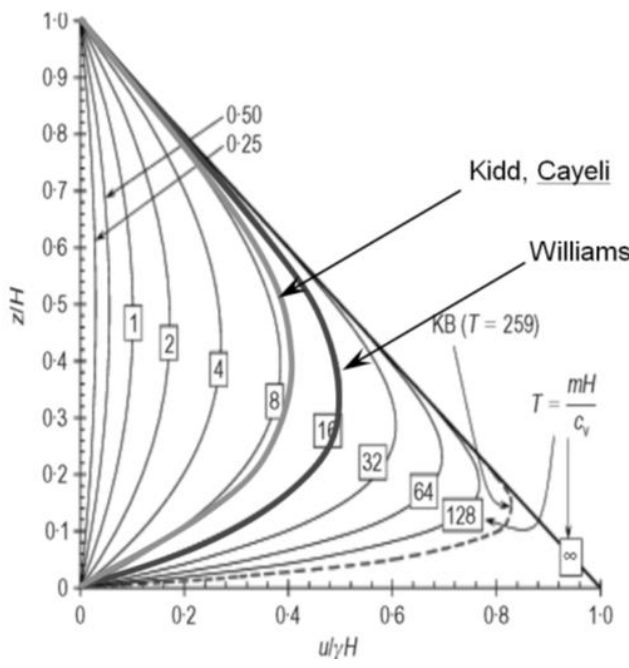

Figure 13 Pore pressures predicted by modified Gibson solution using constant $c_{v}$

Finally, for all three mines it is apparent that any mechanisms that might contribute to lower void ratios and water contents, and therefore more effective binder hydration reactions, are not effectively occurring in the actual backfilling processes used at the mines. Furthermore, it is not at all clear that the backfilling 
processes used could be altered in any way that would promote better density increases during deposition. As a result, at least one of the industry partners in this research has actively worked with a chemical admixture manufacturer to develop cost-effective water reducing agents, similar to those used in the civil construction industry, and these products are now commercially available. The industry partner has already implemented this admixture in their paste plant and the early results are promising.

\section{Conclusions}

The following contributions have been highlighted in this paper:

1. The relationship between bulk properties (dry density, void ratio, water content) and strength (UCS) demonstrated by Fahey et al. (2011) and Yilmaz et al. $(2009,2010,2011)$ was shown to be equally important for the backfill materials at the mines considered in this study.

2. Extensive field monitoring programs, including measurements of EC, temperature, total stress and pore water pressure, were successfully carried out and an integrated interpretation of the data facilitates a better understanding of the hydration processes occurring in the field and contributing to the desired engineering behaviour of the backfill.

3. Both increasing temperature and increasing EC are indicators that hydration has begun, but only a subsequent drop in EC can be correlated to the development of hydration products and the onset of increasing material strength and stiffness.

4. The field instrumentation results, combined with field sampling results, strongly suggest that for well engineered backfills the hydration has already begun by the time effective stresses develop, thereby locking in the bulk properties of the CPB and preventing any strength efficiencies that would otherwise be attained through reduction in void ratio or water content.

5. The use of newly developed water-reducing admixtures may offer a practical modification to traditional mix designs, and it is expected that this will be the focus of much future work.

\section{Acknowledgement}

This work was originally supported by Barrick Gold Corporation, Xstrata Copper Canada, and Inmet Mining Corporation, as well as by the Natural Sciences and Engineering Research Council Canada for the project Geomechanical Design of Cemented Paste Backfill Systems. The UCS experiments reported here were carried out by Arthur Morais Bicalho as part of a summer student placement in 2013 under the Ciência sem Fronteiras (Science Without Borders) program sponsored by the Government of Brazil.

\section{References}

Aref, K 1988, 'A study of the geotechnical characteristics and liquefaction potential of paste backfill', PhD thesis, McGill University. Been, K, Brown, ET \& Hepworth, N 2002, 'Liquefaction potential of paste fill at Neves Corvo mine, Portugal', Transactions of the Institution of Mining and Metallurgy, Section A: Mining Technology, vol. 111, no. 1, pp. 47-58.

Cayouette, J 2003, 'Optimization of the paste backfill plant at Louvicourt mine', CIM Bulletin, vol. 96, no. 1075, pp. 51-7.

Fahey, M, Helinski, M \& Fourie, AB 2010, 'Consolidation in accreting sediments: Gibson's solution applied to backfilling of mine stopes', Géotechnique, vol. 60, no. 11, pp. 877-82.

Fahey, M, Helinski, M \& Fourie, AB 2011, 'Development of specimen curing procedures that account for the influence of effective stress during curing on the strength of cemented paste backfill', Geotechnical and Geological Engineering, vol. 29, no. 5, pp. 709-23.

Galaa, A, Grabinsky, MW \& Bawden, WF 2012, 'Characterizing stiffness development in early age cemented paste backfills with sand in a non-destructive triaxial test', Proceedings of the 65th Canadian Geotechnical Conference.

Gibson, RE 1958, 'The progress of consolidation in a clay layer increasing in thickness with time', Géotechnique, vol. 8, no. 4, pp. 171-83.

Grabinsky, MW, Bawden, WF, Simon, D, Thompson, BT \& Veenstra, RL 2013, 'In situ properties of cemented paste backfill from three mines', Proceedings of the 66th Canadian Geotechnical Conference.

le Roux, K-A, Bawden, WF \& Grabinsky, MW 2005, 'Field properties of cemented paste backfill at the Golden Giant Mine', Transactions of the Institution of Mining and Metallurgy, Section A: Mining Technology, vol. 114, no. 2, pp. 65-80.

Neville, AM 1995, Properties of Concrete, 4th edn, Pearson Education Ltd., UK. 
Simon, D, \& Grabinsky, MW, 2012, 'Characterizing hydration effects in cemented paste backfill using electromagnetic techniques', International Journal of Mining, Reclamation, and Environment, vol. 26, no. 1, pp. 3-28.

Thompson, BD, Bawden, WF \& Grabinsky, MW, 2012, 'In-situ measurements of cemented paste at the Cayeli Mine', Canadian Geotechnical Journal, vol. 49, no. 7, pp. 755-72, viewed 31 March 2014, http://www.nrcresearchpress.com/doi/abs/10. 1139/t2012-040

Thompson, BD, Grabinsky, MW \& Bawden, WF 2011, 'In situ monitoring of cemented paste backfill pressure to increase backfilling efficiency', Canadian Institute of Mining Journal, vol. 2, no. 4, pp. 199-209.

Veenstra, RL 2013, A design procedure for determining the in situ stresses of early age cemented paste backfill, PhD thesis, University of Toronto, viewed 31 March 2014, http://hdl.handle.net/1807/36027.

Veenstra, RL, Grabinsky, MW, Bawden, WF \& Thompson, BD 2013 'A numerical analysis of how permeability affects the development of pore water pressure in early age cemented paste backfill in a backfilled stope', in Y Potvin \& AG Grice (eds), Proceedings of the 11th International Symposium on Mining with Backfill, Australian Centre for Geomechanics, Perth, pp. 83-96.

Yilmaz, E, Belem, T, Benzaazoua, M \& Bussière, B 2010, 'Assessment of the modified CUAPS apparatus to estimate in situ properties of cemented paste backfill', Geotechnical Testing Journal, vol. 33, no. 5, pp. 1-12.

Yilmaz, E, Belem, T, Bussière, B \& Benzaazoua, M 2011, 'Relationship between microstructural properties and compressive strength of consolidated and unconsolidated cemented paste backfills', Cement and Concrete Composites, vol. 33, no. 6, pp. 702-15.

Yilmaz, E, Benzaazoua, M, Belem, T \& Bussière, B 2009, 'Effect of curing under pressure on compressive strength development of cemented paste backfill', Minerals Engineering, vol. 22, no. 9-10, pp. 772-85. 
